\title{
THE NEW LATE COMERS FOR ANTENATAL CARE
}

\author{
JOHN B. McKINLAY, B.A. (Vict., N.Z.) \\ Department of Sociology, Aberdeen University and Medical Sociology Research Unit, Foresterhill Hospital
}

THE Maternity in Great Britain survey (Joint Committee of R.C.O.G., 1948) was one of the first large-scale investigations into both the efficacy of sound antenatal care and the quality of such care received by various social categories in the general population. It was found that, of the 13,500 mothers interviewed, only $125(0.9 \%)$ received no antenatal supervision at all. This group consisted mainly of multiparous wives of manual workers, married women with illegitimate children and unmarried mothers. The authors of this report, after pointing out that expectant mothers who are well-to-do come markedly earlier for antenatal supervision, suggest that it is:

“. . . a reflection of the adequacy of the present antenatal services that only $33 \%$ of agricultural and $37 \%$ of manual workers' wives are supervised during the first term. The unfavourable position of these two groups who together form $70 \%$ of all expectant mothers is particularly evident if only women who are expecting their fourth or higher order birth are considered. Among these the proportion attending during the first three months is $53 \%$ for the professional group, $23 \%$ for the manual workers and $15 \%$ for the agricultural workers" (p. 33).

Another national study, conducted eight years later (Butler and Bonham, 1963), lent support to the findings of this earlier investigation. A recent reanalysis of some of this perinatal mortality survey material shows that, while $60 \%$ of social class I mothers attended for their first antenatal visit before the 17th week of pregnancy, only $50 \%$ of social class III and $39 \%$ of social class V mothers came before this week. When all those coming after the 28th week for their first visit were grouped together we found that late attendance was also related to social class. Whereas only $4 \cdot 14 \%$ of social class I mothers attended after the 28 th week, this increased to $6.36 \%$ through social class III to $11.30 \%$ for social class V. With regard to the receipt of antenatal care, therefore, both of these studies show that, as a group, women of low socio-economic status contribute the highest proportion of underutilizers.

Given these findings and the fact that over 10 years have elapsed since the last national survey, it was thought timely to re-examine the utilization of maternity care facilities, especially as relevant socio- logical data were available in Aberdeen. These data, indeed, are unique, consisting of full medical and social histories of all maternity patients experiencing hospital, nursing home and domiciliary confinements in Aberdeen since 1948. These records have been summarized and stored on 80-column punched cards. Completeness of records is largely ensured through the operation of a centralized hospital-based maternity service in the city. Although choice of antenatal care exists, all National Health Service patients are required to attend the central (hospital) clinic at least once (usually following the confirmation of pregnancy by a general practitioner) when the required information is collected for the records. Furthermore, the existence of very adequate obstetrio facilities in the city has reduced domiciliary cone finements to a minimum-and these few are usually from choice, not necessity (Baird and Thompson? 1969).

In selecting the data for analysis, complete records for three two-year periods were taken, the periods being well spaced to provide a reasonable measure of possible time trends. The analysis was further restricted to legitimate births for two principal reasons. In the first place, for a variety of reasons, records for illegitimate births tend to be less complete. In particular, where there is no husband, allocation to the Registrar General's social class categories presents considerable difficulty, making any comparison in this group, using social class, of doubtful validity. Further, while a relatively high proportion of this population are drawn from outside the Aberdeen district, a comparable proportion of illegitimate pregnancies occurring in Aderdeen are completed elsewhere. It was considered that, because Aberdeen possessed a relatively more efficient maternity service than most areas in Great Britain, o the local situation with respect to the provision of $N$ maternity care may shed some light on the future de- N velopment of maternity care in other areas of the country.

\section{RESULTS}

This paper is primarily concerned with what has 
TABLE I

SOCIAL CLASS COMPOSITION OF MARRIED CHIIDBEARING WOMEN IN ABERDEEN, 1951-66

\begin{tabular}{|c|c|c|c|c|c|c|c|c|c|c|c|c|}
\hline \multirow[b]{3}{*}{$\begin{array}{l}1951-52 \\
1958-59 \\
1965-66\end{array}$} & \multicolumn{12}{|c|}{ Social Class } \\
\hline & \multicolumn{2}{|c|}{ I } & \multicolumn{2}{|c|}{ II } & \multicolumn{2}{|c|}{ IIIa } & \multicolumn{2}{|c|}{ IIIr } & \multicolumn{2}{|c|}{ IV } & \multicolumn{2}{|c|}{$\mathbf{v}$} \\
\hline & $\begin{array}{l}\text { No. } \\
213 \\
262 \\
385\end{array}$ & $\begin{array}{c}3 \% \\
3 \cdot 78 \\
4 \cdot 28 \\
6 \cdot 87\end{array}$ & $\begin{array}{l}\text { No. } \\
506 \\
575 \\
575\end{array}$ & $\begin{array}{r}\% \% \\
8.99 \\
9 \cdot 39 \\
10 \cdot 26\end{array}$ & $\begin{array}{l}\text { No. } \\
671 \\
861 \\
611\end{array}$ & $\begin{array}{r}\% \\
11.92 \\
14.06 \\
10.97\end{array}$ & $\begin{array}{c}\text { No. } \\
\mathbf{2}, 599 \\
\mathbf{2 , 8 8 7} \\
\mathbf{2 , 3 9 1}\end{array}$ & $\begin{array}{r}\% \% \\
46 \cdot 16 \\
47 \cdot 16 \\
42 \cdot 68\end{array}$ & $\begin{array}{l}\text { No. } \\
767 \\
748 \\
947\end{array}$ & $\begin{array}{c}\% \\
13.62 \\
12.29 \\
16.90\end{array}$ & $\begin{array}{l}\text { No. } \\
874 \\
789 \\
693\end{array}$ & $\begin{array}{c}\% \% \\
15.52 \\
12.88 \\
12.37\end{array}$ \\
\hline
\end{tabular}

TABLE II

DISTRIBUTION BY PARITY OF MARRIED CHIIDDBEARING WOMEN IN ABERDEEN, 1951-66

\begin{tabular}{|c|c|c|c|c|c|c|c|c|}
\hline \multirow{3}{*}{ Years } & \multicolumn{8}{|c|}{ Parity } \\
\hline & \multicolumn{2}{|c|}{0} & \multicolumn{2}{|c|}{1} & \multicolumn{2}{|c|}{2} & \multicolumn{2}{|c|}{$3+$} \\
\hline & No. & $\%$ & No. & $\%$ & No. & $\%$ & No. & $\%$ \\
\hline $\begin{array}{l}1951-52 \\
1958-59 \\
1965-66\end{array}$ & $\begin{array}{l}2,023 \\
2,319 \\
2,094\end{array}$ & $\begin{array}{l}35.9 \\
37 \cdot 9 \\
37 \cdot 4\end{array}$ & $\begin{array}{l}1,793 \\
1,946 \\
1,788\end{array}$ & $\begin{array}{l}31.8 \\
31.8 \\
31.9\end{array}$ & $\begin{array}{l}964 \\
975 \\
974\end{array}$ & $\begin{array}{l}17 \cdot 1 \\
15 \cdot 9 \\
17 \cdot 4\end{array}$ & $\begin{array}{l}850 \\
882 \\
746\end{array}$ & $\begin{array}{l}15 \cdot 2 \\
14 \cdot 4 \\
13 \cdot 3\end{array}$ \\
\hline
\end{tabular}

been happening in Aberdeen with regard to the utilization of maternity care services during the period 1951-66. Both Tables I and II show that there has been no marked change in either the social class (as measured by the Registrar General's classification of occupations) or parity composition of the married childbearing population of Aberdeen for the three two-year periods 1951-52, 1958-59 and 1965-66. Table I does show that there has been a slight increase in the percentage of social class I and II women having babies in 1965-66, and a corresponding decrease in the percentage of social class $\mathrm{V}$ women. Table II reveals a slight drop in the percentage of childbearing women who have already had three or more children. This, of course, could be partly accounted for by the social class changes already mentioned with regard to Table I.

The manner in which the age composition of married childbearing women in Aberdeen has changed over the three two-year periods is illustrated in Table III. Given that the social class and parity compositions appear to have remained relatively constant, there seems to have been a remarkable change in the age distribution of married child- bearing women in Aberdeen during the period 195166. Whereas in 1951-52, women in the youngest age group (15-19 years) accounted for only $4.10 \%$ of the total births, in 1965-66 they contributed $11.49 \%$. Conversely, in the oldest age range (30 years and over) the trend in the same years was from $32.97 \%$ to $23.87 \%$.

As all further analysis of the data was concerned with the investigation of trends, the frequently employed mean week of first visit was not the most sensitive statistic to use as it is primarily a measure of central tendency. Instead, the percentage of women attending before the 17th week or after the 28th week was used in order to summarize the data more meaningfully. These weeks were taken because it was considered that more extreme cut-off points (e.g., before the 12th week and after the 32 nd week) would include only very atypical cases, giving a rather biased percentage which would not, therefore, reflect general trends.

An initial investigation of social class differences in antenatal visiting patterns, using the percentage attending before the 17th week, did not reveal any clear changes over the year groups taken. (However,

TABLE III

CHANGING AGE COMPOSITION OF MARRIED CHLDBEARING WOMEN IN ABERDEEN, $1951-66$

\begin{tabular}{|c|c|c|c|c|c|c|c|}
\hline \multirow{3}{*}{ Years } & \multicolumn{6}{|c|}{ Age (yrs) } & \multirow{3}{*}{ Total } \\
\hline & \multicolumn{2}{|c|}{$15-19$} & \multicolumn{2}{|c|}{$20-23$} & \multicolumn{2}{|c|}{$30+$} & \\
\hline & No. & $\%$ & No. & $\%$ & No. & $\%$ & \\
\hline $\begin{array}{l}1951-52 \\
1958-59 \\
1965-66\end{array}$ & $\begin{array}{l}231 \\
378 \\
644\end{array}$ & $\begin{array}{r}4 \cdot 10 \\
6 \cdot 17 \\
11 \cdot 49\end{array}$ & $\begin{array}{l}3,543 \\
4,117 \\
3,621\end{array}$ & $\begin{array}{l}62 \cdot 93 \\
67 \cdot 25 \\
64 \cdot 64\end{array}$ & $\begin{array}{l}1,856 \\
1,627 \\
1,337\end{array}$ & $\begin{array}{l}32.97 \\
26 \cdot 58 \\
23.87\end{array}$ & $\begin{array}{l}5,630 \\
6,122 \\
5,602\end{array}$ \\
\hline
\end{tabular}


TABLE IV

PERCENTAGE OP PARITY $3+$ WOMEN, COMING BEFORE THE 1TTH WEEK, BY SOCLAI CLASS $1951-66$

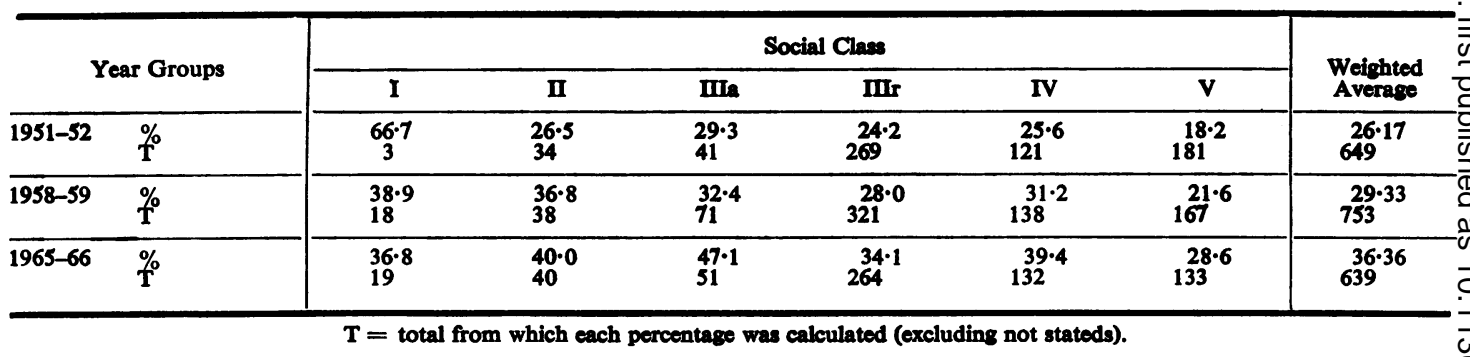

the inverse relationship between social class and week of first antenatal visit remained intact.) While social classes IIIr to V revealed no time trends at all, social classes I to IIIa did show a slight tendency towards a later first week of attendance. These percentages may, of course, be influenced by the age differences already noted in Table III, as well as by other uncontrollable factors such as relatively high rates of geographical mobility in social classes I to IIIa and its consequent effect on attendance. In view of this, it was decided to eliminate the social class effect from subsequent analyses (see statistical note to Table $V$ for the method).

We referred earlier to the fact that attendance before the 17th week of gestation has been positively related to the mother's social class. Social class V women (i.e., the wives of unskilled manual workers) experiencing a fourth or subsequent pregnancy are usually considered a 'hard core' group for which, in terms of antenatal care, little can be done. Using parity $3+$ as an extreme group for comparison, therefore, the percentages of Table IV were calculated. Clearly, this 'hard core' group in social class V has shown a marked improvement over the three two-year periods considered. While in 1951-52 only $18 \%$ came before the 17th week for their first antenatal visit, $22 \%$ and $29 \%$ came before this week $\triangle$ in 1958-59 and 1965-66 respectively. These figures $\overrightarrow{-r}$ would suggest that the problem of providing early antenatal care to this known high-risk group may응 not be as intractable as was previously thought. However, although there has been an improvement ${ }_{\Phi}^{T}$ in this old 'hard core' multiparous group, Table IV을 shows that, in 1965-66, they continue to make the least use of antenatal services in Aberdeen and, one would suspect, elsewhere.

Having demonstrated the existence of a marke ${ }_{\text {do }}$ social class difference in the week of first visit decided to consider the effects of age and parity. Table $\mathrm{V}$ presents an analysis by age and parity of $\bar{\partial}$ these trends in week of first antenatal visiting for the three two-year periods, eliminating social class $\mathbb{D}$ effects. A consistent increase in the proportion coming before the 17th week is apparent only음 for those women experiencing a fourth or subsequent pregnancy (in both age groups). This trend could, in part, reflect a reduction in the proportion of grand multiparae in the general population; $a \stackrel{\curvearrowright}{\triangle}$

Table V

PERCENTAGE OF MARRIED WOMEN IN EACH AGE AND PARITY GROUP ATTENDING FOR FIRST ANTENATAL VISTT BEFORE THE 1TTH WEEK, TAKING INTO ACCOUNT SOCIAI CLASS COMPOSITION OP POPULATION*

\begin{tabular}{|c|c|c|c|c|c|c|c|c|c|c|c|c|}
\hline \multirow{4}{*}{ Year Groups } & \multicolumn{12}{|c|}{ Parity } \\
\hline & \multicolumn{3}{|c|}{0} & \multicolumn{3}{|c|}{1} & \multicolumn{3}{|c|}{2} & \multicolumn{3}{|c|}{$3+$} \\
\hline & \multicolumn{12}{|c|}{ Age (yrs) } \\
\hline & 15-19 & $20-29$ & $30+$ & $15-19$ & $20-29$ & $30+$ & $15-19$ & $20-29$ & $30+$ & $15-19$ & $20-29$ & $30+$ \\
\hline $\begin{array}{l}1951-52 \\
1958-59 \\
1965-66\end{array}$ & $\begin{array}{l}44 \cdot 1 \\
38 \cdot 8 \\
31 \cdot 2\end{array}$ & $\begin{array}{l}68 \cdot 0 \\
64 \cdot 6 \\
61 \cdot 7\end{array}$ & $\begin{array}{l}65.7 \\
65.6 \\
65.6\end{array}$ & $\begin{array}{l}21 \cdot 7 \\
27 \cdot 5 \\
22 \cdot 2\end{array}$ & $\begin{array}{l}47 \cdot 5 \\
42 \cdot 9 \\
51 \cdot 4\end{array}$ & $\begin{array}{l}61.4 \\
60.9 \\
57 \cdot 1\end{array}$ & $\overline{\overline{4}}$ & $\begin{array}{l}36 \cdot 1 \\
28 \cdot 5 \\
41 \cdot 9\end{array}$ & $\begin{array}{l}44 \cdot 4 \\
52 \cdot 3 \\
44 \cdot 6\end{array}$ & $\bar{z}$ & $\begin{array}{l}25 \cdot 2 \\
27 \cdot 5 \\
31 \cdot 2\end{array}$ & $\begin{array}{l}26 \cdot 2 \\
31 \cdot 0 \\
39 \cdot 3\end{array}$ \\
\hline
\end{tabular}

A Note on the Statlstical Method for Tables $V$ and VI: The percentages in Tables V and VI were caleulated separately for each ase and $ᄃ$ parity category within each social class and year group. These percentages were then averaged over the six social class categories within each $(1)$ year group to give the results presented in Tables V and VI. This average, however, was weighted for each social class according to its aize. $\mathrm{S}$ In calculating these weights use was made of the general stability of the social class composition of the population (see Table 1 over the three. two-year periods taken. The numbers for each social class were, therefore, summed over the three periods, and proportions of the population $T$ total were calculated. These proportions were then used as common weights for all three periods. Those categories shown with a dash in Tables $\mathrm{V}$ and VI had no cases in the sub-categories before summation. 
reduction which may, of course, have been influenced by the policy of post-partum sterilization of grand multiparae in Aberdeen city. However, the trend remains substantial, again reflecting the improved antenatal care accorded women of known high risk.

Despite this improvement, however, there has been a noticeable decline in early visiting for women under 30 years of age experiencing their first pregnancy. This trend is especially marked for the 15-19 year age group where the percentage coming before the 17th week drops from 44 to 31 over the period 1951-66. This remarkable reversal of trends was, of course, obscured completely when we considered these percentages for social class only. An interesting explanation for a large proportion of this decrease may be an increase in the number of pre-nuptial conceptions in the younger age groups (Illsley, 1956).

The two younger age groups for parities 1 and 2 show a slight overall improvement in attendance before the 17th week, although the older women (age 30+) in these parity groups show no improvement at all. The percentages for these two parity groups exhibit a generally static situation. It will be of considerable interest, however, to follow up these parity groups (i.e., those in second and third pregnancies) from future data in order to ascertain the effect of the recent backward trend in young primiparae on their subsequent behaviour.

These general developments, with regard to utilization, discussed in relation to Table $\mathrm{V}$ appear to find confirmation in Table VI which presents the percentages of women in each age and parity group who attend for their first antenatal visit after the 28th week. There is a clear decrease in the percentage of women experiencing a fourth or subsequent pregnancy, in both age groups, coming after their 28th week of pregnancy. This is, of course, consistent with the increased percentage of these women attending before the 17th week noted in Table V.

Parities 1 and 2. (excluding the 15-19 year old age group) show a consistent improvement also, although this is not as marked as for the grand multiparae already described. These improvements for parities 1 and 2 are, however, clearer than the trends noted for the same groups in connection with Table V. It would seem that these improvements result, to a large extent, from the general policy in Aberdeen of directing attention towards known high-risk groups (i.e., women of high parity who are also relatively older).

Table VI, like Table V, shows that the nulliparous group and the 15-19 year old primiparae are atypical. Although there has not been a reversal in the percentages coming after the 28th week for these groups, no change at all is apparent in comparison with a marked trend towards improvement in the remaining parity and age categories. This phenomenon may reflect a lack of recognition of this young, relatively high-risk group of nulliparae and, for the 15-19 year old primiparae, a continuation of the habit of delay of antenatal care during their first pregnancy into their second pregnancy, which is already manifesting itself.

It is interesting to note that, despite considerable improvement over the periods given, the grand multiparae high-risk groups still have the largest percentages of women attending for their first antenatal visit after the 28 th week of gestation.

\section{SOME IMPLICATIONS}

There are clearly a number of medical and administrative implications associated with the trends noted in this paper. Firstly, it has been established that, at least in terms of perinatal and maternal mortality and morbidity, women are at lower obstetric risk during a second or third pregnancy than they are when they are undergoing a first pregnancy. It would seem, therefore, if only on the grounds of maternal complications and pregnancy wastage, that we should refocus attention even more on that group of young primigravidae who, as we have noted, are showing increasing tendencies to underutilize maternity care facilities.

TABLE VI

PERCENTAGE OF MARRIED WOMEN IN EACH AGE AND PARITY GROUP ATTENDING FOR FIRST ANTBNATAL VISIT AFTER THE 28TH WEEK, TAKING INTO ACCOUNT SOCIAL CLASS COMPOSITION OF POPULATION

\begin{tabular}{|c|c|c|c|c|c|c|c|c|c|c|c|c|}
\hline \multirow{4}{*}{ Year Group } & \multicolumn{12}{|c|}{ Parity } \\
\hline & \multicolumn{3}{|c|}{0} & \multicolumn{3}{|c|}{1} & \multicolumn{3}{|c|}{2} & \multicolumn{3}{|c|}{$3+$} \\
\hline & \multicolumn{12}{|c|}{ Age (yrs) } \\
\hline & $15-19$ & $20-29$ & $30+$ & $15-19$ & $20-29$ & $30+$ & $15-19$ & $20-29$ & $30+$ & $15-19$ & $20-29$ & $30+$ \\
\hline $\begin{array}{l}1951-52 \\
1958-59 \\
1965-66\end{array}$ & $\begin{array}{l}6 \cdot 54 \\
6 \cdot 26 \\
6 \cdot 86\end{array}$ & $\begin{array}{l}3 \cdot 81 \\
3 \cdot 55 \\
3 \cdot 21\end{array}$ & $\begin{array}{l}4 \cdot 94 \\
4 \cdot 45 \\
4 \cdot 94\end{array}$ & $\begin{array}{r}19 \cdot 71 \\
9 \cdot 25 \\
20 \cdot 40\end{array}$ & $\begin{array}{l}8 \cdot 05 \\
6 \cdot 55 \\
5 \cdot 40\end{array}$ & $\begin{array}{l}4 \cdot 62 \\
3 \cdot 56 \\
2 \cdot 96\end{array}$ & $\overline{7}$ & $\begin{array}{r}13 \cdot 62 \\
12.97 \\
6.93\end{array}$ & $\begin{array}{r}10 \cdot 94 \\
6 \cdot 37 \\
5 \cdot 39\end{array}$ & I & $\begin{array}{l}29 \cdot 81 \\
22 \cdot 43 \\
12 \cdot 37\end{array}$ & $\begin{array}{l}24 \cdot 30 \\
19 \cdot 93 \\
11 \cdot 19\end{array}$ \\
\hline
\end{tabular}


Secondly, it may be that, through failure of the services to recognize the problems of this group of primigravidae, generally inadequate care is likely to result. A woman from this group, having experienced normal parturition without complications, is likely to perceive antenatal care as somewhat irrelevant and unnecessary, and to perpetuate her 'unsatisfactory' behaviour through subsequent pregnancies. Moreover, it is reasonable to assume $a$ priori, that these influences will be more likely to affect women of low socio-economic status. This implies that certain individuals and groups (who may be at higher obstetric risk in relation to others) may become frequently habituated to episodic and fragmented care, thereby creating a new, increasing, socio-medical problem in the near future.

Thirdly, at a more general level, there is the sociological problem of the stigma associated with prenuptial conception which may be a major factor contributing to the underutilization of antenatal services by the young primigravidae. This problem, it seems, may be aggravated by the present existence of a system of organizing maternity care, in which women must present themselves at a centralized clinic. Women of higher socio-economic status, by being able to opt for private consultations, may be able to avoid this to some extent. Women of lower socio-economic status, on the other hand, for mainly financial reasons are constricted in their choice of agencies to the centralized clinic and their general practitioner. In other words, stigma, as a factor contributing towards underutilization, may have a differential impact by social class, and indeed may be more influential than women's perceptions of the benefits of antenatal care. It should be noted that the influence of such a stigma may decrease as prenuptial conception becomes an increasingly frequent occurrence in all social groups. However, stigma can only partially explain the presence of this trend. A detailed prospective examination of additional possible explanations is at present nearing completion in Aberdeen (McKinlay, 1970).

In conclusion, it appears that both the opposing trends outlined in this paper differ in magnitude for different socio-economic groups, the lower status groups remaining the main contributors to the problem of underutilization. While the overall maternity care position of multiparae, especially in the older age groups, has improved considerably, social class V still remains the worst group in this respect. Moreover, in the recently emerged trend towards underutilization by primiparae, low socioeconomic status again appears to be an important factor, within the present system. This phenomenon would seem to have organizational implications for the delivery of adequate maternity care to different $\stackrel{\infty}{\infty}$ sub-groups within the community (McKinlay, 1969).

\section{SUMMARY}

The presence of a unique set of records in Aberdeen has enabled the phenomenon of underutilization during the period 1951-66 to be examined in some detail. In general, although there has been considerable improvement in some social categories, others seem to be either perpetuating to a lesser extent a tradition of under-use or beginning to $\vec{\circ}$ exhibit a new pattern of under-use. Clearly there has $\overrightarrow{\vec{H}}$ been considerable improvement in the position of $\omega_{\sim}$ the social class $V$ grand multiparae (the old "hard $\frac{D}{\circ}$ core') but as a social category they still remain late ? comers. If early antenatal care during pregnancy (i.e., attendance before the 17th week) is important and can influence both maternal and infant mortality if and morbidity, then there has been a noticeable 0 regression in the health behaviour of the young primigravidae over the period 1951-66. Some possible 7 explanations for this apparently emerging trend are briefly discussed.

The research described in this paper is financed by a grant from the Nuffield Provincial Hospitals Trust. $\delta \overrightarrow{0}$ would like to thank Professor Raymond Illsley and M William Bytheway for encouragement and valuable criticisms. To Mrs Sonja McKinlay special thanks axe expressed for valuable comments.

\section{REFERENCES}

BAIRD, D., and Thompson, A. M. (1969) Reduction of $\stackrel{\square}{\unrhd}$ Perinatal Mortality by Improving Standards of $\overrightarrow{\vec{F}}$ Obstetric Care. Chapter 14, Perinatal Problems. 의 Livingstone, Edinburgh.

Butler, N. R., and Bonham, D. G. (1963). Perinatal Mortality. Livingstone, Edinburgh.

ILLSLEY, R. (1956) The duration of antenatal care, The Med. Offr., 107-111.

Joint Committee of Royal College of Obstetricians aND GyNaECOLOGISTS AND THE POPUlation INVESTIGATION COMMTTTE (1948). Maternity in Great Britain. Oxford University Press, London.

MCKINLAY, J. B. (1969). Better Maternity Care for Whom ... . Med. Offr., 20, 275-276.

(1970). A brief description of a study on the utilization of maternity and child welfare services by a lower $D$ working class subculture. Social Science and Medicine, in press.

\section{APPENDIX}

For a number of quite obvious reasons it was not surprising to find, when analysing the Aberdeen material, a high proportion of cases who, for some attributes, have to be grouped together as "not stated". The proportion of cases so classified was so high in some instances as to require comment. 
TABLE A1

CASES NOT STATED FOR WEEK OF FIRST ANTENATAL VISIT AND SOCIAL CLASS AS A PERCENTAGE OF THE YEAR GROUP TOTALS

\begin{tabular}{c|c|c|c}
\hline & \multicolumn{2}{|c|}{ Not Stated } & \multirow{2}{*}{ Total } \\
\cline { 2 - 3 } Groups & Social Class & Week of First Visit & \\
\cline { 2 - 3 } $1951-52$ & $2 \cdot 03$ & $21 \cdot 11$ & 5,753 \\
$1958-59$ & 0.52 & $9 \cdot 76$ & 6,148 \\
$1965-66$ & 0.04 & $8 \cdot 46$ & 5,530 \\
\hline
\end{tabular}

Table A1 shows that the percentage of cases whose social class could not be stated decreased from only $2.03 \%$ in 1951-52 to a negligible $0.04 \%$ in 1965-66. Clearly, the number of cases whose social class is unstated is not a great problem when analysing this material, especially in relation to those whose week of first visit is unstatable. Although there has clearly been a marked decrease in the overall proportion of cases whose week of first visit is not stated (from $21 \%$ in $1951-52$ through $9.76 \%$ to $8.46 \%$ in $1958-59$ and 1965-66 respectively) it still remains high and worthy of further investigation.

Two main points emerge from Table A2 which looks in a little more detail at those cases whose week of first visit was unstated. Firstly, it appears that there is a much higher proportion of 'not stateds' for the first year group (1951-52) than for either of the later two (1958-59 and 1965-66) which show very little change. It would appear from this table that comparisons involving the first year group are of doubtful validity (e.g., $45 \%$ and $40 \%$ for social classes I and II respectively were 'not stated'). Secondly, Table A2 demonstrates that the proportion of cases whose week of first visit is unstated remains consistently higher in the upper two social classes (16\% and $15 \%$ for social classes $I$ and $I I$ in $1965-66$ against $11 \%$ in social class $V$ ). This phenomenon may be partly explained by either the known high rate of geographic mobility or perhaps the tendency towards private consultations for women in social classes I and II. It is, of course, possible that these trends may influence either way the adverse young primigravida trend noted above. Nevertheless this trend, as we have noted, is so marked that it is unlikely to disappear entirely if 'not stateds' were taken into account. Moreover it seems that the proportion of 'not stateds' in the other social classes is low enough not to affect, to any real extent, the trends presented above. Thus it seems most probable that the high number of 'not stateds', particularly for social classes I and II, has contributed considerably to the inconsistencies shown by these groups in the previous analyses of week of first antenatal visit. It should be pointed out that these inconsistencies may mask trends or other inconsistencies, and that, with this in view, detailed investigation of these 'not stateds' is under way.

TABLE A2

CASES WHOSE WEEK OF FIRST VISIT WAS NOT STATED AS A PERCENTAGE OF THE TOTAL FOR EACH SOCIAL CLASS

\begin{tabular}{|c|c|c|c|c|c|c|c|}
\hline \multirow{2}{*}{ Year Group } & & \multicolumn{6}{|c|}{ Social Class } \\
\hline & & I & II & IIIa & IIIr & IV & $\mathbf{v}$ \\
\hline $1951-52$ & $\%$ & 214 & $\begin{array}{l}39 \cdot 92 \\
506\end{array}$ & $\begin{array}{l}18 \cdot 78 \\
671\end{array}$ & $2,599^{17 \cdot 20}$ & $\frac{14 \cdot 64}{772}$ & 874 \\
\hline 1958-59 & $\%$ & 262 & $20 \cdot 10$ & $861^{7 \cdot 90}$ & $2,887^{6 \cdot 34}$ & 745 & 789 \\
\hline $1965-66$ & $\%$ & 311 & 575 & $611^{7 \cdot 69}$ & $2,391^{5 \cdot 94}$ & $947^{7 \cdot 39}$ & 693 \\
\hline
\end{tabular}

